\title{
Saving public universities
}

Higher education in the United States is shared between public and private institutions. The former, such as the University of Michigan or the University of California, receive annual funding from their states. The latter, such as Stanford University or Harvard, rely on private revenue sources, especially student fees and income from endowments. Both types compete for research grants from the federal and state governments. The public universities were founded and are funded by their respective states to promote the public interest, especially agricultural, economic and social development.

In his book Unmaking the Public University, Christopher Newfield, professor

Unmaking the Public University: The Forty-Year Assault on the Middle Class by Christopher Newfield Harvard University Press: 2008. 408 pp. $\$ 29.95, € 19.95$, €22.50

of a new middle class. The new cohort is composed of multiracial, progressive and upwardly mobile graduates of public universities. They are the knowledge workers in the knowledge economy. The public universities taught them the collaborative working styles, research skills and technical abilities that enabled the success of cutting-edge companies such as those in Silicon Valley, California. Newfield suggests that cultural conservatives targeted this group because they threatened the power of the traditional business and political elites.

Newfield identifies the major adversaries of this new middle class and the public university as the same conservative culture of English at the University of California in Santa Barbara, draws attention to the drop in funding for public universities since the 1970s. Its decline, he argues contentiously, is a result of a campaign by "cultural conservatives" who brand these institutions as breeding grounds for a 'liberal' middle class.

Newfield's latest work succeeds his 2003 book Ivy and Industry (Duke University Press), which explored the problematic relationship between business and US universities. He argued that the liberal-arts tradition and capitalist culture are contradictory forces that create conflicts for both the academy and the students who go on to comprise much of the middle class. He challenged the modern North American university to promote the humanities while drawing on the benefits of business organization and dispensing with its negative aspects.

Now, Newfield builds on his earlier work by presenting a complex, historical narrative warriors who attacked the liberal influence on campus. His most striking claim is that for the latter, "The ultimate prize was the reduced cost and status of the middle class that the public university created". Newfield describes how conservatives, in league with powerful figures such as Ronald Reagan, a governor of California and later US president, influenced the reduction of funding for public universities, crippling this new middle class. The author also blames universities for compromising their institutional independence through their business dealings with government and corporations.

Newfield suggests some obvious remedies. Racial equality must be re-established as a primary national goal; the public universities must broaden their access and raise their academic quality; funding must be increased; and human development must be promoted together with economic opportunity. Yet he neglects key issues that are familiar to those engaged in the current debates over public higher education, making his thesis questionable.

A more plausible reason for the decreasing financial support for public universities, for example, is the perennial battle for scarce resources in state-government budgets. Public higher education must compete for funds with escalating health-care costs, increasing primary- and secondary-school needs, and rising demands by other government agencies. Thus, public universities have responded by supplementing their state funds through additional fund-raising, joint projects with private companies and higher student fees.

Newfield gives only one passing reference to the important and growing phenomenon of community colleges, which offer two-year academic and vocational degrees to students who cannot or choose not to attend a four-year course at a college or university. Nationally, there are approximately 6.7 million community-college students, and a significant number move on to further study on four-year degree programmes. Given that community colleges serve as a major gateway to a senior college education, this is a critical omission in the book.

Another weakness is the lack of historical background. Unlike privately funded institutions, state funding has made economic development an integral part of the public university's mission for their home state. Prominent in this regard are the 'land grant' universities created by the Morrill Acts of 1862 and 1890 , which were required to emphasize instruction in the agricultural and mechanical arts and sciences.

One could get the impression from reading Unmaking the Public University that the cultural battle has been one-sided. The book makes no mention of the major national higher-educational organizations such as the American Association of State Colleges and Universities, the National Association of
Genetic Engineering and Life on a Biotech Planet. Her story is one-sided, but it is well researched and she recommends a feasible system of risk analysis. The book will alarm some and anger others, but the debate is urgently needed.

Jerry Ravetz, fellow of the James Martin Institute, University of Oxford, UK.

\footnotetext{
Undermining Science by Seth Shulman

(Univ. California Press, 2006)

Seth Shulman argues that George W. Bush's science policies recall those of Trofim Lysenko under Josef Stalin. The details are not pretty, the reporting is thorough and the evidence has not been credibly contested. Republican candidate John McCain might read it to see the extent to which neoconservative infrastructure is already in place in US science agencies, making it easier for him to continue the same policies without seeming to. His record on some science issues has been good, but his
}

recent opinions, from energy to creationism in schools, have been drifting towards those of Bush. Democrat candidate Barack Obama might use Shulman's book to discover which recent science-agency appointees passed the test of right-wing fealty rather than that of scientific objectivity, thereby suggesting where he might make replacements. But such a task will not be easy. Shulman reports that the present administration has so thoroughly sown loyalists of questionable competence into science bodies - from NASA to the US Weights and Measures division - that it will take a considerable effort to root them out.

Kevin Padian, professor of integrative biology and curator of the Museum of Paleontology, University of California, Berkeley.

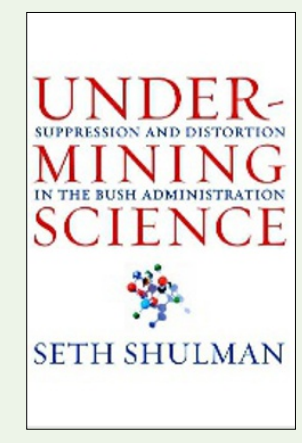


State Universities and Land-Grant Colleges, or the American Council on Education, which have led the fight for the funding of public higher education at local, state and national levels.

Has the public university been unmade and Newfield's new middle class damaged? Hardly. Government funding has decreased in public universities, but they still have a critical role in US society. In the prestigious Association of American Universities, composed of the 60 leading research universities in the nation, more than half are public. The middle class is suffering some economic reversals, but the reasons are complex. Public higher education will continue to have a leading role in providing access to a goodquality education at an affordable price, for those who wish to improve their standard of living and quality of life.

John B. Clark is interim chancellor at the State University of New York, State University Plaza, Albany, New York 12246, USA.

e-mail:john.clark@suny.edu

\section{Q\&A: Science sketched out}

The annual UK Big Draw festival, a month of nationwide workshops and talks launched this weekend in London, teaches people how to 'see' through drawing. Terry Rosenberg, head of design at Goldsmiths, University of London, explains how gaining skills in life drawing can help scientists perceive the world and communicate their results.

\section{Drawing on Life \\ Wellcome Collection, London \\ 26-28 September 2008 \\ University College London \\ 27 September 2008 \\ www.thebigdraw.org}

\section{Why should scientists learn to draw?}

Drawing can improve our understanding of perception by isolating different parts of the perceptual apparatus. When I first learned to draw, I would break up a scene into patches and try to reproduce each one. But this doesn't work - the eyes are constantly adjusting, the head moving, the light changing.

One teaching technique I use is to draw by moving the pencil in the same way that the eyes scan. This highlights the way the brain gathers information by making connections between different elements of the scene. Alberto Giacometti and other artists have done this more formally by plotting out such spatial relationships, into which a drawing can then be situated.

\section{Leonardo Da Vinci studied anatomy using life drawing. Might students do so today?} Drawing moves from the general to the particular - looking at how the anatomy is articulated in practice; the positions, posture and movement of one bone over the other. I ask students to draw a posed skeleton, then draw a model in the same pose, building the muscles on top of the bones and resolving the tensions between them. You can then go back and infer what is inside the model.

Colouring and copying diagrams of the human body, as students do, is still drawing. They seem like strategies for rote learning, but when you look at an object and sketch it, you bring all your previous experience and knowledge to that moment.

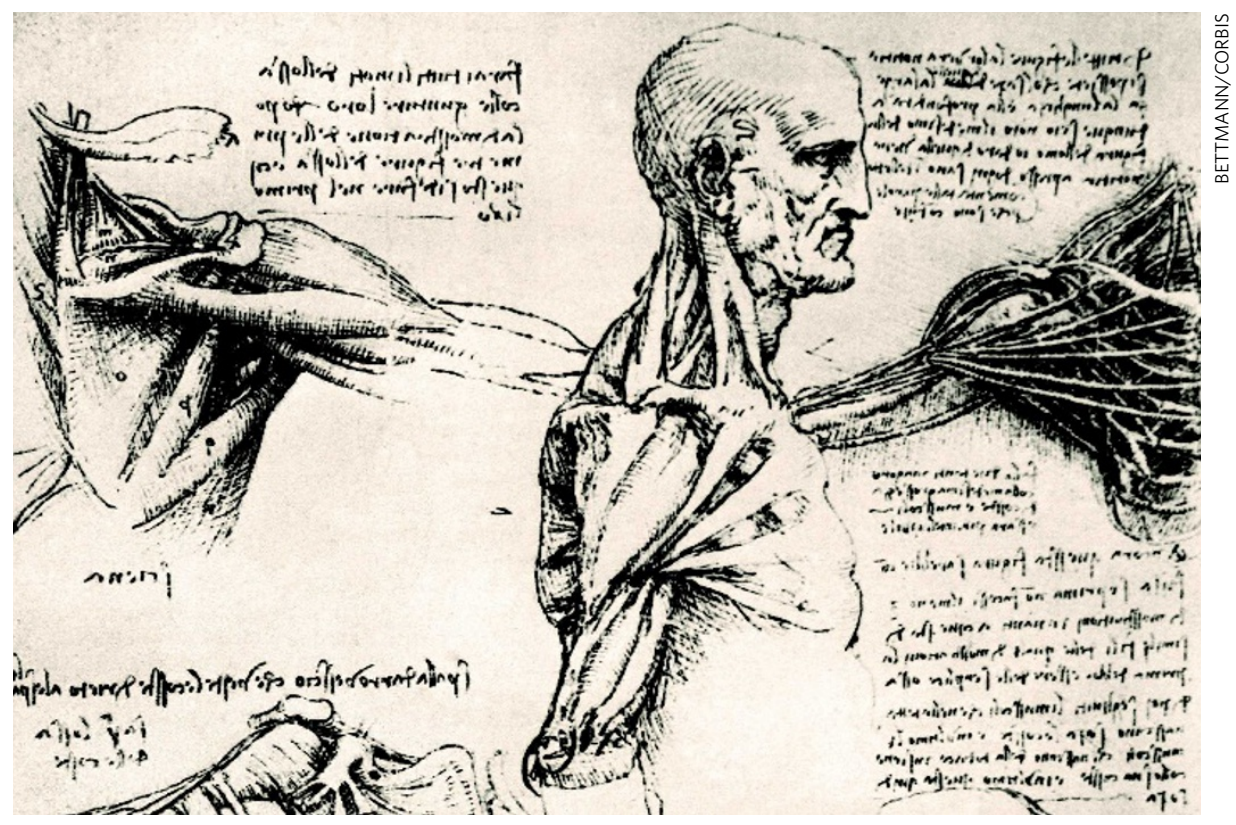

Life drawing is a useful learning method for anatomy students today - as it was for Leonardo da Vinci.

Can the act of drawing generate ideas? Einstein claimed that his theories of relativity were merely hunches followed up by rigorous method. But how did he get the hunch? My design research looks at how laying out connections in time and space on the page can trigger new ideas. Rather than just seeking trends, our brains make nonlinear connections and homologies between juxtaposed objects, and original ideas result.

\section{Might scientists use diagrams more effectively to communicate ideas?} Diagrams offer a quick way of making a hypothesis. Canonical representations such as hieroglyphs, where the symbol for a face might show it in profile, are often used. They communicate what is most important, but can ignore other elements of the underlying structure - the profile face hieroglyph misses out an eye, for example. And diagrams can also be driven too much by aesthetics: even anatomical diagrams use metaphors of the landscape, such as rivers, peaks and valleys. Scientists might learn from design research, which explores how information can be best conveyed spatially - as in the schematic map of the London Underground, for example.

Does drawing try to represent the 'truth'? Subjective knowledge always intercedes in the processes that bind the hand to the eye. It has been said that drawing 'cleans things', but there is no ultimate image - every drawing tells you something different.

Interview by Louise Whiteley, a computational neuroscientist and writer based in London. She is deputy editor of The Liberal magazine. e-mail: lewhiteley@gmail.com 